\title{
Hyperbaric oxygen therapy in the management of severe leg ulcers from prolidase deficiency
}

\author{
Michelangelo Vestita, ${ }^{1}$ Giuseppe Giudice, ${ }^{1}$ Domenico Bonamonte ${ }^{2}$
}

${ }^{1}$ Unit of Plastic and Reconstructive Surgery, Universita degli Studi di Bari Dipartimento Emergenza e Trapianti di Organi, Bari, Italy ${ }^{2}$ Dipartimento di Scienze Biomediche e Oncologia Umana, Universit̃̃ degli Studi di Bari, Bari, Italy

\section{Correspondence to}

Dr Michelangelo Vestita, michelangelovestita@gmail. com

Accepted 18 December 2016
CrossMark

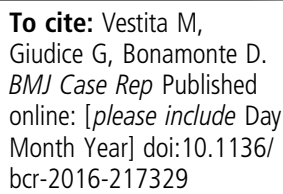

\section{DESCRIPTION}

A 31-year-old man presented to our attention showing infected ulcerative lesions with pseudoepitheliomatous hyperplasia of legs and feet, which rendered him unable to walk or to even stand. At the age of 8 , he had been diagnosed with prolidase deficiency disorder, based on high levels of imidodipeptiduria and reduced enzymatic activity of erythrocytic prolidase.

At the time of hospitalisation, the patient presented diffuse lower limbs lymphedema, with sockshaped ulcerative-hyperplastic areas, involving the medial and distal third of legs and feet. Such lesions were exudative and variably deep, showed irregular edges, increased tissue consistency and hyperplastic surrounding skin (figures 1 and 2). To confirm the diagnosis, genetic analysis and prolidase enzymatic activity assay were performed, showing homozygosis for the (c.1342G $>$ A (p. Gly488Arg)) mutation, and a non-determinable prolidase activity in cutaneous fibroblasts. Multiple microbiological examinations from cutaneous swabs turned out to be constantly positive for Pseudomonas aeruginosa, occasionally positive for various bacteria and negative for mycetes. On the basis of this, the patient was put on intravenous meropenem, tobramycin and daptomycin, while topically applying in a trial-and-error fashion a series of products, such as povidone iodine 50\% solution, 1/1000 potassium permanganate, gentamycin cream, iodoform gauze and a thin polyurethane membrane coated with a layer of an acrylic adhesive that contains $2 \%$ available iodine. None of these therapeutic options were successful in eradicating $P$. aeruginosa.

Given the poor therapeutic results, in an attempt to minimise ulcers extension and to decrease bacterial population, hyperbaric oxygen therapy

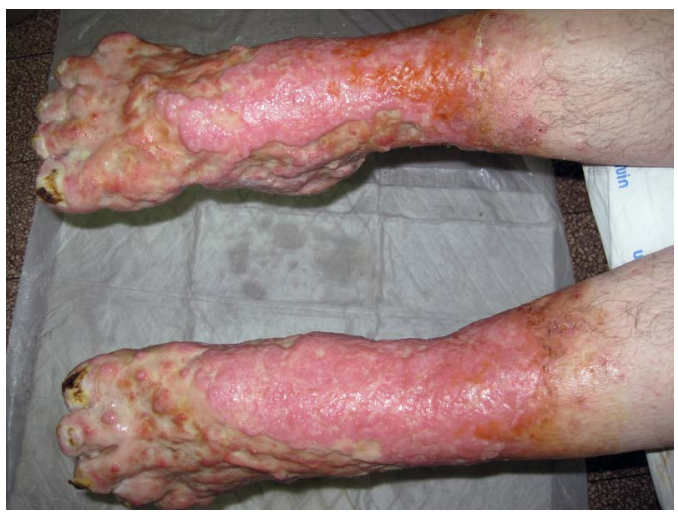

Figure 1 Exudative sock-shaped ulcerative-hyperplastic areas involving the lower limbs.

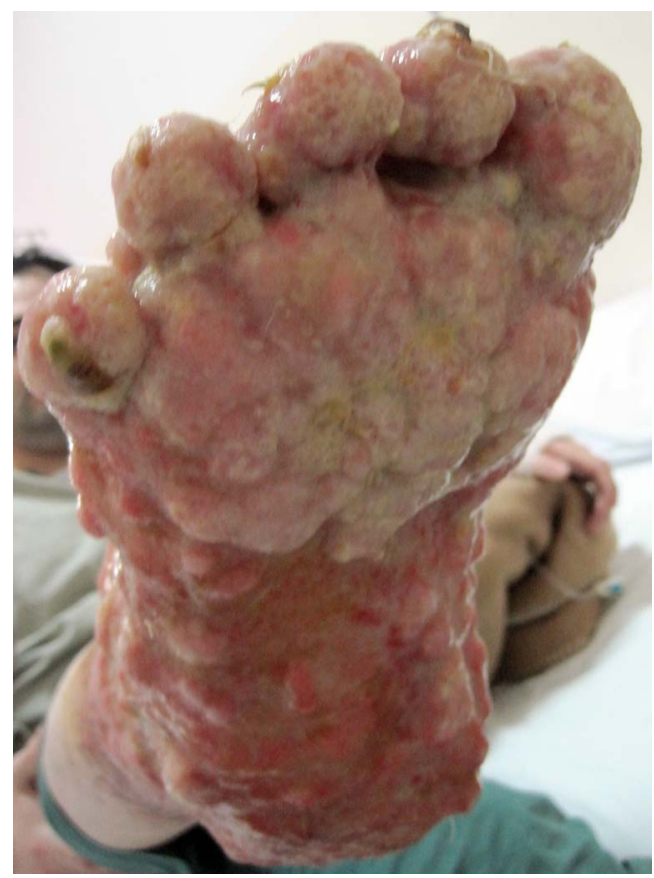

Figure 2 Detail of the right foot.

(HBOT) was suggested and shortly after initiated; the patient's ECG and chest X-rays showed no contraindication. At the time of writing, the patient has had two cycles of HBOT. A cycle involves eight sessions of $60 \mathrm{~min}$ in duration, each split into three phases: compression at 15 metres/2.5 atmosphere absolute, prescribed time at pressure (three $20 \mathrm{~min}$ $100 \%$ oxygen stints) and decompression. After two

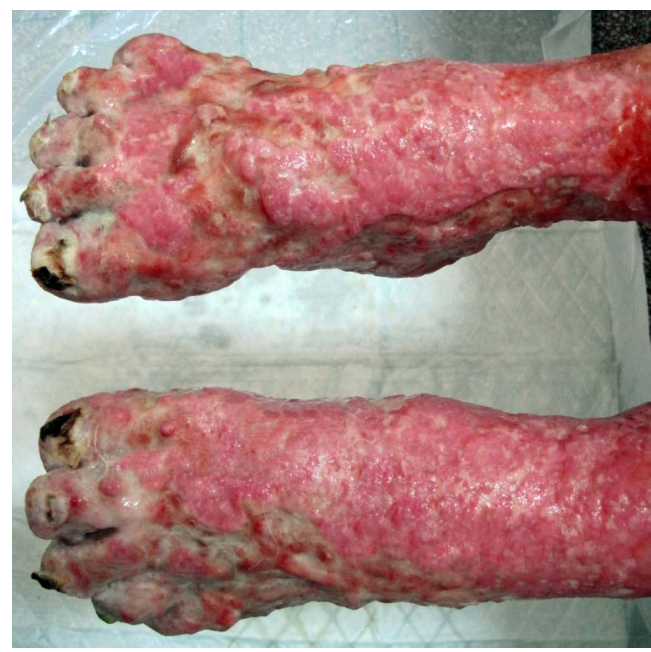

Figure 3 After two cycles of HBOT. Notice the newly formed areas of granulation tissue and the decreased exudation. 
cycles of HBOT, a modest reduction in the extension of ulcerative-necrotic areas was obtained, with distinct new areas of granulation tissue, as well as a noticeable decrease in exudation and acrid odour (figure 3). Multiple control swabs were negative for $P$. aeruginosa. Moreover, our patient, previously unhopeful, manifested a clear improvement of his state of mind.

Prolidase deficiency is a rare autosomal-recessive disease, caused by mutations in the PEPD gene on chromosome 19 (19q12-q13.11), which presents with multisystem features, including chronic leg ulcers of variable severity. ${ }^{12}$

HBOT efficacy in chronic wounds is widely reported as is, to a lesser degree, its antibacterial capability. ${ }^{3}$ The latter implies an

\section{Learning points}

- Prolidase deficiency is a rare autosomal-recessive disease, caused by mutations in the PEPD gene, which presents with multisystem features, including chronic leg ulcers of variable severity.

- Hyperbaric oxygen therapy is useful in promoting wound healing of chronic wounds and also has antibacterial capability, through enhancement of polymorphonuclear function, bacterial clearance and antibiotic penetration, as well as through a direct toxic effect on anaerobic bacteria.

- On the basis of our our report, in cases of severe ulcerative lesions with multiresistant $P$. aeruginosa infection, hyperbaric oxygen therapy can be highly useful in eradicating the bacterium. improvement in polymorphonuclear function, bacterial clearance and antibiotic penetration, as well as a direct toxic effect on anaerobic bacteria.

To the best of our knowledge, this is the first reported case of prolidase deficiency-related leg ulcers managed with HBOT. In our case, HBOT was only marginally useful in reducing the extension of ulcerative lesions, but especially beneficial in eradicating $P$. aeruginosa, which was resistant to traditional therapies; this translated in an improvement of prognosis and quality of life.

On the basis of our observation, we suggest that HBOT should be considered as an effective option in the long-term management of leg ulcers associated with prolidase deficiency.

\section{Twitter Follow Michelangelo Vestita @Michelangelo Vestita}

Contributors MV is responsible for conception and final approval of the study, and involved in writing the manuscript. GG involved in drafting the manuscript and in final approval of it. DB is responsible for conception of the study and approved the manuscript. All authors agreed to be accountable for the article and to ensure that all questions regarding the accuracy or integrity of the article are investigated and resolved.

Competing interests None declared.

Patient consent Obtained.

Provenance and peer review Not commissioned; externally peer reviewed.

\section{REFERENCES}

1 Endo F, Matsuda I. Molecular basis of prolidase (peptidase D) deficiency. Mol Biol Med 1991;8:117-27.

2 Trent JT, Kirsner RS. Leg ulcers secondary to prolidase deficiency. Adv Skin Wound Care 2004;17:468-72.

3 Goldstein LJ. Hyperbaric oxygen for chronic wounds. Dermatol Ther 2013;26:207-14.

Copyright 2017 BMJ Publishing Group. All rights reserved. For permission to reuse any of this content visit http://group.bmj.com/group/rights-licensing/permissions.

BMJ Case Report Fellows may re-use this article for personal use and teaching without any further permission.

Become a Fellow of BMJ Case Reports today and you can:

- Submit as many cases as you like

- Enjoy fast sympathetic peer review and rapid publication of accepted articles

- Access all the published articles

- Re-use any of the published material for personal use and teaching without further permission

For information on Institutional Fellowships contact consortiasales@bmjgroup.com

Visit casereports.bmj.com for more articles like this and to become a Fellow 